\title{
Editorial
}

\section{Emerging Research Ideas in Orthopaedics and Musculoskeletal Medicine}

\author{
J. Todd R. Lawrence MD, PhD
}

Published online: 19 February 2011

(C) The Association of Bone and Joint Surgeons (R 2011

The practice of musculoskeletal medicine continues to evolve rapidly. In this issue, we debut a new feature article section titled, "Emerging Research Ideas in Orthopaedics and Musculoskeletal Medicine." These articles, spanning a wide array of topics-basic molecular biology, imaging modalities and research tools, healthcare delivery and clinical therapeutics, among others-unify around a common theme: hypotheses with a significant potential to change the practice of orthopaedic surgery and musculoskeletal medicine in the near future.

Articles in this "Emerging Ideas" series defy easy categorization. They are neither reports of original scientific studies nor are they review articles. The format of these papers will be new to readers-it was new to us. These papers begin with the authors' exposition of a novel hypothesis. The authors then define the scientific process to test that hypothesis and the roadmap for eventually implementing the ideas to give the reader a sense of how feasible the proposed program might be and the hurdles which might impede bringing the work to clinical practice. Finally, the authors aim to succinctly place their program in the context of prior work and future developments with a discussion on what establishing that hypothesis might mean to the community of orthopaedic surgeons and musculoskeletal researchers.

This series can be thought of as "Proceedings of the Grant Writing Workshops", as the articles were solicited from participants in grant writing workshops sponsored by the Orthopaedic Research and Education Foundation, the Orthopaedic Research Society, The American Academy of Orthopaedic Surgeons, and the Bone and Joint Decade. Because participation in these writing workshops is limited to researchers with defined research ideas, it is hoped that the papers offered here represent more than idle musings. However, some of the authors, as you will see, are contemplating completely innovative approaches with no guarantee of success.

We trust that this series provides a service to readers, authors, and the community of orthopaedic and musculoskeletal researchers alike. Readers, we hope, will be edified and informed by these early reports. Authors, in turn, are offered the chance to "plant the flag" and rightly claim public credit for their ideas. Finally, we expect that these articles can foster a discussion among researchers in the field and perhaps even establish new collaborations. Feedback and suggestions on the endeavor are welcome.
J. T. R. Lawrence ( $\square)$

Division of Orthopaedic Surgery, Children's Hospital

of Philadelphia, 2 Wood Building, 34th \& Civic Center

Boulevard, Philadelphia, PA 19104, USA

e-mail: lawrencej@email.chop.edu; j.todd.lawrence@gmail.com 